\title{
PHANTOM EXPERIENCES FOLLOWING AMPUTATION IN CHILDHOOD
}

\author{
MARIANNE L. SIMMEL' \\ From Brandeis University and Massachusetts General Hospital, Boston, Massachusetts
}

When a person has lost an arm or leg in an accident, or as the result of surgery, he typically continues to feel the lost extremity as if it were still present. On first awaking from the anaesthesia such a patient may not believe that the leg has actually been removed until he can convince himself by looking under the covers. Even once he knows beyond doubt that it is gone, the foot of the amputated leg may itch and, as he reaches down to scratch it, he reaches for an empty space. He may feel the bed sheets on the arm or leg, he may feel a mild, perhaps pleasant tingling, a phenomenon which Henderson and Smyth regard as basic (Henderson and Smyth, 1948), or, more rarely, he may have pain. He may feel that he can wiggle his fingers or toes, flex or extend the wrist or ankle, and that he can perform these movements more or less at will. Despite his knowledge of the amputation which has been performed the patient may 'forget' and reach out with his missing hand to grasp something, or to steady himself, or he may step on the phantom foot and fall.

The earliest published account of phantom experiences following amputation is probably that of Ambroise Paré, the great French military surgeon of the sixteenth century (Keynes, 1952). A hundred years later Descartes, who evidently did not know Paré's treatise, described the sensations of a girl whose arm had been amputated at the elbow and complained about pain in the phantom fingers (Riese, 1958). Melville's scene between Captain Ahab and the ship's carpenter indicates that early in the nineteenth century, and probably long before that, there was a certain amount of popular knowledge concerning amputation phantoms (Melville, 1959). The carpenter, puzzled though he is by Captain Ahab's story, has heard 'that a dismasted man never entirely loses the feeling of his old spar, but it will be still pricking him at times'.

The first systematic and fairly detailed description was given by Guéniot just a hundred years ago (Guéniot, 1861). Soon afterwards appeared Weir

tPresent address: Graduate Faculty, New School for Social Research, 66 West 12th Street, New York City. N.Y.
Mitchell's classical article, based on the observations of several hundred Civil War veterans then residing at the 'Stump Hospital' in Philadelphia (Mitchell, 1871). Mitchell coined the several terms 'phantom limb', 'ghost limb', and 'sensory ghost', which are still in use today.

The intriguing nature of the phantom is attested by the large number of publications on this topic which have appeared during the last ninety years. ${ }^{2}$ The central argument of much of that literature concerns the 'peripheral' versus the 'central' origin of the phantom, a controversy which, at least in its more naĩve form, is essentially out-dated. Not outdated, however, is Henry Head's notion of a cognitive schema of the body, a concept which he applied only incidentally to the amputation phantom (Head and Holmes, 1912). To be sure, already Captain Ahab saw lurking behind the phantom an invisible double of the whole person, and Guéniot (1861) had come close to anticipating Head's schema. But it was Head who explicitly formulated the concept and spelled out the two main characteristics of the body schema: its genesis as a function of past sensory experience, and its active determination of precepts initiated by newly arriving sensory inputs. This notion has gained fairly wide acceptance among students of phantom phenomena (e.g. Pick, 1915; Schilder, 1950; Hécaen and Ajuriaguerra, 1952; Russell, 1959), despite the fact that some of its implications remain to be clarified (Oldfield and Zangwill, 1942a and b, 1943). Foremost among these is the concept of past experience.

If the amputation phantom is to be regarded as a sign of a body schema which persists despite the physical alteration wrought by amputation, and if one assumes that such a schema is built up from past sensory experience, then the problem of phantom experience following amputation in childhood is a crucial one. In an earlier publication I have shown that phantoms are absent for extremities missing from birth, and have argued that this is so because the absent limb has never been experienced, and thus has never been a part of the body schema (Simmel,

$2 \mathrm{~A}$ detailed review of the literature is in preparation. 


\section{TABLE I}

COMPOSITION OF FOUR GROUPS OF SUBJECTS

\begin{tabular}{|c|c|c|c|c|c|c|c|c|c|c|c|c|c|c|c|}
\hline \multirow{3}{*}{$\begin{array}{l}\text { Group } \\
\text { of } \\
\text { Subjects }\end{array}$} & \multicolumn{2}{|l|}{ Total } & \multicolumn{3}{|c|}{$\operatorname{Sex}$} & \multirow{2}{*}{\multicolumn{2}{|c|}{$\begin{array}{l}\text { Age (yr.) at } \\
\text { Amputation }\end{array}$}} & \multirow{2}{*}{\multicolumn{2}{|c|}{$\begin{array}{l}\text { Age (yr.) at } \\
\text { Interview }\end{array}$}} & \multicolumn{3}{|c|}{ Prosthesis } & \multicolumn{3}{|c|}{ Side of Amputation } \\
\hline & Subjects & No. of & $M$ & $F$ & $?$ & & & & & Yes & No & $?$ & $R$ & L. & \\
\hline & & Amputations & & & & Range & Median & Range & Median & & & & & & latera \\
\hline $\begin{array}{l}\text { a } \\
\mathbf{b} \\
\mathbf{c} \\
\mathbf{d}\end{array}$ & $\begin{array}{l}27 \\
41 \\
39 \\
29\end{array}$ & $\begin{array}{l}31 \\
45 \\
41 \\
33\end{array}$ & $\begin{array}{l}14 \\
29 \\
31 \\
12\end{array}$ & $\begin{array}{r}4 \\
12 \\
8 \\
17\end{array}$ & 9 & $\begin{array}{l}0-2 \text { to } 9 \\
0-3 \text { to } 9-11 \\
10-6 \text { to } 18 \\
2 \mathrm{hr} \text {. to } 17 \mathrm{yr} \text {. }\end{array}$ & $\begin{array}{r}5-0 \\
6-0 \\
15-6 \\
8-1\end{array}$ & $\begin{array}{r}3-6 \text { to } 45 \\
4-3 \text { to } 60 \\
11-7 \text { to } 72 \\
4-2 \text { to } 34\end{array}$ & $\begin{array}{l}18 \\
6-0 \\
17 \\
12-0\end{array}$ & $\begin{array}{l}12 \\
35 \\
32 \\
25\end{array}$ & $\begin{array}{l}1 \\
6 \\
4 \\
5\end{array}$ & $\begin{array}{r}18 \\
4 \\
5 \\
3\end{array}$ & $\begin{array}{l}11 \\
22 \\
20 \\
18\end{array}$ & $\begin{array}{r}4 \\
15 \\
17 \\
7\end{array}$ & $\begin{array}{l}4 \\
4 \\
2 \\
4\end{array}$ \\
\hline
\end{tabular}

1961). I am now addressing myself to the question of how much and what kind of experience does seem to be necessary for an extremity to become part of the body schema, and for a phantom to result upon amputation. Leaving aside the details of phantom experience per se, I shall simply try to indicate the presence or absence of phantoms as a function of earlier sensory experience.

\section{SUBJECTS AND PROCEDURE}

Data are available from four groups of subjects who had suffered the loss of one or more extremities in childhood or youth. Table I presents a summary of the vital statistics and other relevant information for each of these groups. Further details concerning individual subjects are given in Tables II, III, and VI.

GROUP A In this group are included 27 subjects having undergone a total of 31 amputations of previously normal extremities before the age of 10 years. None of these was examined personally by the writer. For 26 of the subjects the material was culled from the existing literature; a report concerning the remaining subject was received from a physician who had examined this patient some years ago. In general the information given for this group of subjects is relatively sketchy and often incomplete.

GROUP B This group contains 41 subjects who had undergone a total of 45 amputations of previously normal extremities before the age of 10 years.

GROUP C This group is composed of 39 subjects having undergone a total of 41 amputations of previously normal extremities during their second decade of life. It may be of interest to note that one half of the amputations in this group resulted from accidents involving gun play or explosions of fireworks or home-made bombs.

GROUP D There are 29 subjects in this group, witn a total of 33 amputations of congenitally malformed extremities which had been surgically removed before the age of 20 years, largely in order to fit a useful prosthesis.

All subjects in groups $b, c$, and d were examined personally by me. With few exceptions they were seen between 1956 and 1958 in the Amputee Clinic of the Research and
Educational Hospitals at the University of Illinois. ${ }^{3}$ The patients attended this clinic primarily for the prescription and adjustment of artificial limbs. Within the limits of a sometimes complicated schedule they represent successive clinic cases.

The older patients were interviewed individually. Information about the younger patients was obtained both from the children themselves and from relatives who accompanied them to the clinic and were present during the interview. Most patients were seen only once, though a few were questioned on repeated occasions.

Two considerations guided the courses of the interview. First, in view of the subjective nature of the phantom it was important for the examiner not to suggest to the subject phenomena which the latter had never experienced. Secondly, a subject with a phantom is aware of the discrepancy between his perceptual experience and the fact of the loss of the limb, and he may be hesitant to talk about an experience contradicted by physical reality, lest he be regarded as untrustworthy or even non compos mentis. Actually, neither of these turned out to be a major problem. The phantom which follows amputation is a vivid experience and, given the opportunity, most patients mention it spontaneously. By zontrast, even intelligent patients who have never had this experience seem to have some difficulty in understanding what the examiner is trying to talk about, even though they may have heard about phantoms from acquaintances who had lost a limb, or from other patients in the waiting room. It appears, therefore, that the role of suggestion cannot have been a very significant one. Similarly, while a few subjects were initially hesitant to admit to phantom experiences, they seemed to be considerably relieved when they discovered that the examiner knew about phantoms and did not consider them as anything unusual.

A typical interview proceeded as follows: At the outset the subject was asked to recount the circumstances leading to and surrounding the amputation. Most subjects had either lost consciousness at the time of the accident or had undergone surgery under general anaesthesia. At this juncture the examiner asked: 'What happened when you woke up?' More often than not the reply was: 'I didn't think the leg was gone, I could still feel my toes,''I looked and it was gone but I still felt it, I feel it now,''I could feel my toes, I could wiggle them the same as you can wiggle yours,'-'I could still feel my hand and I

II am indebted to Dr. Claude Lambert of the Department of Orthopedic Surgery, College of Medicine, University of Illinois, for allowing me to participate in this clinic and to interview his patients. 
TABLE I-continued

COMPOSITION OF FOUR GROUPS OF SUBJECTS

Reason for Amputation

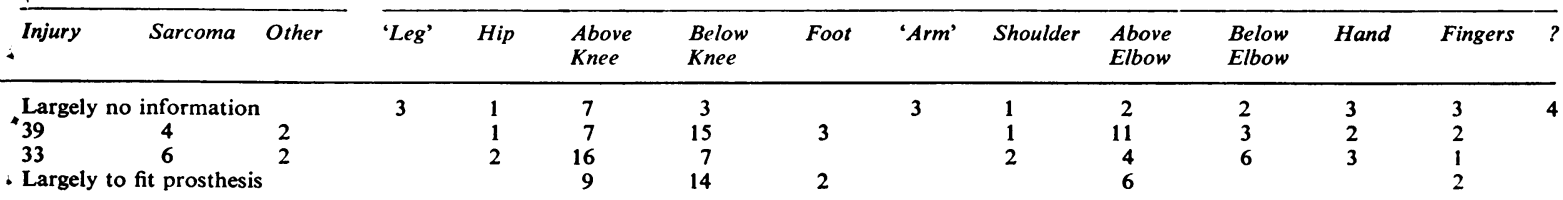

.$>$

feel it now,'-'After you get used to it, you know it's gone but you have the feeling it is there,' etc.

When phantoms were not mentioned spontaneously at this time or during the account of subsequent events, the examiner said: 'Some people who have lost an arm (leg, etc.) have told me that it happens that they still feel the hand (fingers, toes, etc.) even though they know perfectly well that it is gone. Has it ever felt that way to you?' Thereupon some subjects immediately described their own phantom experiences, while to others this question did not seem to make much sense. Only rarely was the response indicative of a conscious denial, such as 'I don't think about it, I might have felt the toes but it's just your imagination, it is all in your head.' After a little reassurance, even these exceptional individuals usually came forth with quite vivid descriptions of their phantoms.

Once the phantom had been mentioned, either spon- taneously by the subject or 'suggestively' by the examiner, and irrespective of the subject's reply to the latter, the interview continued. The examiner enquired in detail about the various parts which the subject experienced, their position, motility, pain, itching, etc., and he was asked also about incidents of 'forgetting' when he might have reached to grasp something with the phantom hand, or to steady himself, or when he might have stepped on the phantom foot and fallen. Such incidents were often reported spontaneously, and the subject was given free rein to describe his experiences. For the younger subjects it was often the parents who supplied these details or who, having heard about phantoms elsewhere, confirmed the child's indication of the presence or absence of phantoms by giving specific examples. In a few instances the parents recalled that the child had talked about phantoms soon after amputation, even though the youngster himself did not recall such experiences.

TABLE II

CASES OF PHANTOMS AFTER AMPUTATION IN CHILDHOOD REPORTED IN THE LITERATURE

\begin{tabular}{|c|c|c|c|c|c|}
\hline \multirow[t]{2}{*}{ Source } & \multicolumn{2}{|c|}{ Amputation } & \multirow{2}{*}{$\begin{array}{l}\text { Interview } \\
\text { Age }\end{array}$} & \multirow[t]{2}{*}{ Phantom } & \\
\hline & Age & Site & & & \\
\hline $\begin{array}{l}\text { Souques and Poisot (1905) 'D' } \\
\text { Browder and Gallagher (1948) } \\
\text { Cronholm (1951) Case } 82 \\
\text { Critchley (1955) } \\
\text { Cronholm (1951) Case } 11 \\
\text { Browder and Gallagher (1948) } \\
\text { Steelman (1952) } \\
\text { Browder and Gallagher (1948) } \\
\text { Watson and Johnson (1958) } \\
\text { Cronholm (1951) Case 43 } \\
\text { Cronholm (1951) Case 70 } \\
\text { Browder and Gallagher (1948) } \\
\text { Cronholm (1951) Case 27 } \\
\text { Riese and Bruck (1950) } \\
\text { Riese and Bruck (1950) } \\
\text { Riese and Bruck (1950) } \\
\text { Riese and Bruck (1950) } \\
\text { Cronholm (1951) Case 92 } \\
\text { Cronholm (1951) Case } 6 \\
\text { Ewalt et al. (1947) } \\
\text { Souques and Poisot (1905) 'Beb' } \\
\text { Cronholm (1951) Case 17 } \\
\text { Cronholm (1951) Case } 36 \\
\text { Cronholm (1951) Case } 2 \\
\text { Cronholm (1951) Case 87 } \\
\text { Livingston (1945) } \\
\text { Hécaen and Ajuriaguerra (1952) }\end{array}$ & $\begin{array}{l}2 \mathrm{mth} . \\
9 \mathrm{wk} . \\
1 \mathrm{yr} . \\
1-6 \\
2 \mathrm{yr} . \\
2-6 \\
3 \mathrm{yr} . \\
3-6 \\
3-9 \\
4 \mathrm{yr} . \\
4 \mathrm{yr} . \\
4 \mathrm{yr} . \\
5 \mathrm{yr} . \\
6 \mathrm{yr} . \\
7 \mathrm{yr} . \\
7 \mathrm{yr} . \\
7 \mathrm{yr} . \\
7 \mathrm{yr} . \\
7 \mathrm{yr} . \\
7 \mathrm{yr} . \\
7 \mathrm{yr} . \\
8 \mathrm{yr} . \\
8 \mathrm{yr} . \\
9 \mathrm{yr} . \\
9 \mathrm{yr} . \\
9 \mathrm{yr} . \\
9 \mathrm{yr} .\end{array}$ & $\begin{array}{l}\text { Both hands } \\
\text { Arm } \\
\text { Right, above elbow } \\
\text { ? } \\
\text { Right, above knee } \\
\text { Right arm and right leg } \\
\text { Right arm } \\
\text { Right arm and left arm } \\
\text { Right, above knee } \\
\text { Left, below elbow } \\
\text { Right, below knee } \\
\text { Leg } \\
\text { Right, above knee } \\
\text { Left leg } \\
\text { Finger } \\
\text { Finger } \\
\text { ? } \\
\text { Left, below knee } \\
\text { Right, below elbow } \\
\text { ? } \\
\text { Right, above knee } \\
\text { Right, above elbow } \\
\text { Right, below knee } \\
\text { Left shoulder } \\
\text { Bilateral, above knee } \\
\text { ? } \\
\text { Wrist }\end{array}$ & $\begin{array}{l}16 \mathrm{yr} . \\
19 \mathrm{yr} . \\
17 \mathrm{yr} . \\
3-6 \\
18 \mathrm{yr} . \\
29 \mathrm{yr} . \\
38 \mathrm{yr} . \\
45 \mathrm{yr} . \\
3-9 \\
18 \mathrm{yr} . \\
18 \mathrm{yr} . \\
? \\
24 \mathrm{yr} . \\
9+\mathrm{yr} . \\
? \\
? \\
9+\mathrm{yr} . \\
31 \mathrm{yr} . \\
16 \mathrm{yr} . \\
40 \mathrm{yr} . \\
14 \mathrm{yr} . \\
17 \mathrm{yr} \text {. } \\
16 \mathrm{yr} . \\
14 \mathrm{yr} \text {. } \\
39 \mathrm{yr} \text {. } \\
42 \mathrm{yr} . \\
?\end{array}$ & $\begin{array}{l}\text { Absent } \\
\text { Absent } \\
\text { Absent } \\
\text { Absent } \\
\text { Absent } \\
\text { Absent } \\
\text { Absent } \\
\text { Absent } \\
\text { Absent }\end{array}$ & $\begin{array}{l}\text { Present }{ }^{2} \\
\text { Present } \\
\text { Present } \\
\text { Present } \\
\text { Present } \\
\text { Present } \\
\text { Present } \\
\text { Present } \\
\text { Present } \\
\text { Present }\end{array}$ \\
\hline
\end{tabular}

${ }^{1}$ Amputation at $6 \mathrm{yr}$. was not followed by a phantom until after surgical revision at 9 yr. when the phantom appeared.

'The phantom appeared spontaneously at age 9 yr., more than two years after amputation and without intervening surgery. 
RESULTS

PHANTOM EXPERIENCES AFTER AMPUTATION OF PREVIOUSLY NORMAL EXTREMITIES The findings for the individuals in group a are presented in Table II, and those from group $b$ in Table III. No such table is given for subjects of group c, since every individual of the group reported phantom experiences following amputation, experiences which persisted to the time of the interview in all but five cases. The results for groups a, b, and c, are combined in Table IV.

Table IV shows the general trend very clearly. Phantoms are reported for only a small proportion of extremities lost before the age of 4 years; thereafter their incidence rises rapidly until phantoms follow predictably on amputation at or above the age of 8 years. The distributions for groups $a$ and $b$ are essentially alike, and the results of group c confirm the findings for the older subjects of groups a and $b$.

The reader may be surprised by the finding of any reports of phantoms following amputation in infancy and earliest childhood. Case 348 (Table III) at the age of 4 years and 3 months presents convincing evidence of a phantom foot following below-knee amputation at 6 months of age. The same was

TABLE III

PHANTOMS AFTER AMPUTATIONS OF NORMAL EXTREMITIES IN CHILDHOOD

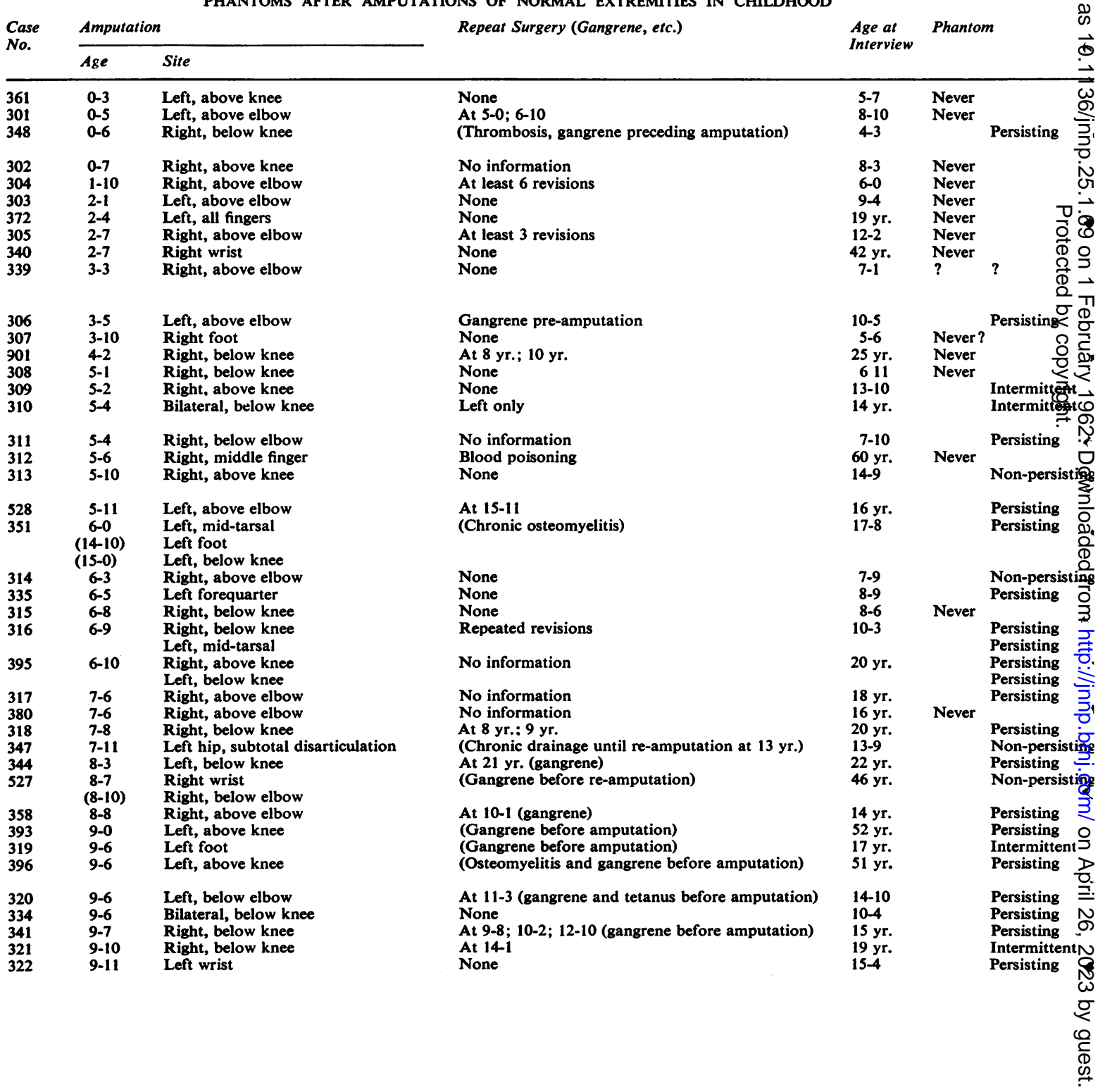


apparently true of Critchley's case (Table II) with an amputation at 18 months who was seen at the age of $3 \frac{1}{2}$ years. An additional case of persisting phantoms after amputation at 18 months appears among the subjects with amputation of congenitally malformed extremitics to be discussed below. From a statistical point of view these are exceptional cases, but in fact they may be crucial. One is tempted to speculate that these exceptions are really instances of a norm which can no longer be uncovered in the majority of infantile amputees, even though they may not persist as they do in the older amputee. Furthermore, both the phantom and the memory of the phantom experience may be affected to a similar degree by the relative mnemonic instability of the very young. This hypothesis receives at least some support from a comparison of amputation-interview intervals for subjects who report phantoms and those who do not. Table $\mathrm{V}$ presents ranges and medians of these intervals. Evidently the distributions overlap considerably; yet, for amputations before the age of 8 years, the obtained difference is statistically significant (Mann-Whitney $U$ test, $p=0 \cdot 01$ ).

PHANTOM EXPERIENCES AFTER AMPUTATION OF CONGENITALLY MALFORMED EXTREMITIES The detailed

TABLE III-continued

PHANTOMS AFTER AMPUTATIONS OF NORMAL EXTREMITIES IN CHILDHOOD

Comments

Occasionally complains of stump pain

Amputation followed severe burns. No details

Father: 'He knows he doesn't have it, but at times he says his foot hurts and he means the foot. He also talks about the stub (stump) but that's different'. Has pointed to foot of prosthesis, saying his foot hurt

Had never walked before receiving prosthesis at $2 \mathrm{yr} .10 \mathrm{mth}$.

Amputation two months after partial excision of tumour

Amputation five days after wringer injury

Knows of phantoms: remembers no such experience. Mother recalls no evidence of phantom

Amputation two weeks after mangle injury

Knows of phantoms; remembers no such experience. Older sister recalls no evidence

First interview, parents report no phantom. Subject agrees to 'suggestion' (?) that she can move her fingers; asked if she can make a fist, delays, 'tries', then says, 'Yes'. Asked to spread fingers, delays, 'tries', says she cannot. Is wearing prosthesis. On two later occasions, child and parents report, 'no phantom ever'

Sometimes feels as if he can open prosthetic hook just by spreading phantom fingers

Parents think amputation 'didn't register for a few days'. No other evidence of phantom

Student; has heard about phantoms, comments, 'It must be psychological'. Denial?

No evidence of phantom from subject or mother. Mother knows about phantoms

Felt whole leg until 6 or 7 . Now only occasional itching of toes. No telescoping

Can always feel legs. However, feels them less vividly and less often than immediately after amputation. Right phantom foot faded before left ('the one I had the operation on')

Parents certain subject feels hand, can move fingers. Subject 'shows' how she wiggles fingers

Amputation two to three months after accident. Reliability of information questionable

Amputation three weeks after car accident. Mother reports vivid phantom for at least a few months after amputation. Subject apparently does not remember early phantom experience

Feels fingers and elbow. No telescoping

Vivid phantom after first amputation, gradually fading. Now feels toes at stump

Vivid phantom after amputation. Intermittent at 7-1. 'No feeling of fingers any more' at 7-9

Amputation 8-9 months after onset of swelling. Feels arm, elbow, hand-can move fingers

Mother knows about phantoms. Has asked subject repeatedly

Sometimes thinks he can 'get up and walk without artificial legs'. Feels feet and toes. Has fallen repeatedly

Feels right toes, left toes, and heel. Recently sat without prostheses, 'jumped up to walk', fell. When he first mentioned phantoms to family they thought he was crazy

Initially felt whole arm, now only thumb, at end of prosthesis. No telescoping

Reliability of report questionable due to low intelligence of subject and father

Feels foot, can move toes and ankle. 'Prosthesis feels like natural leg'

In hospital, 'I asked my mother to scratch my toes and she told me I didn't have the leg'. Phantom only for three to four weeks after amputation 'Still feels like I have the whole leg as long as I have the prosthesis on'

Phantom fingers and hand for about 2 yr. after amputation. Nothing now

Apparently felt elbow immediately after amputation, now only hand and fingers. No telescoping

Amputation two weeks after crushing injury. Feels toes, instep, sole. No telescoping

Foot in cast for six weeks between accident and amputation

Osteomyelitis, gangrene, high fever, severe pain for four weeks before amputation. Vivid phantom toes in stump ever since he can remember. No other phantom parts

Feels hand at stump. Can move fingers

Feels he can wiggle all toes. Toes at stumps, not in tips of prosthetic shoes

Amputation 17 days after car accident. Feels only toes at stump

On waking after amputation, 'Did not know the leg was off-leg felt numb'. Feels toes from time to time; can move them

Feels whole hand, all fingers. Sometimes they hurt or itch. Has tried to scratch them 
TABLE IV

PHANTOMS, AFTER AMPUTATION IN CHILDHOOD IN GROUPS A, B, AND C

\begin{tabular}{|c|c|c|c|c|c|c|c|}
\hline Age at Amputation & Total & & & & & ent & \\
\hline $\begin{array}{l}\quad<2-0 \\
2-0 \text { to } 3-11 \\
4-0 \text { to } 5-11 \\
6-0 \text { to } 7-11 \\
8-0 \text { to } 9-11\end{array}$ & $\begin{array}{l}10 \\
14 \\
13 \\
20 \\
19\end{array}$ & $\begin{array}{l}a \\
4 \\
5 \\
2 \\
3 \\
0\end{array}$ & $\begin{array}{l}\mathrm{b} \\
4 \\
5 \frac{1^{1}}{1} \\
3 \\
2 \\
0\end{array}$ & $\begin{array}{r}\% \\
80 \\
75 \\
39 \\
25 \\
0\end{array}$ & $\begin{array}{l}a \\
1 \\
2 \\
2 \\
5 \\
7\end{array}$ & $\begin{array}{l}b \\
1 \\
1 \frac{1}{2}^{1} \\
6 \\
10 \\
12\end{array}$ & $\begin{array}{l}\% \\
20 \\
25 \\
61 \\
75 \\
100\end{array}$ \\
\hline $\begin{array}{l}\text { Group } c \\
10-0 \text { to } 19-11\end{array}$ & 41 & - & $\mathbf{0}$ & 0 & - & 41 & 100 \\
\hline
\end{tabular}

'Since the protocols for Case 339 (Table III) did not justify a definite decision, it has been entered as $\frac{1}{2}$ in both columns.

TABLE V

AMPUTATION-INTERVIEW INTERVALS FOR 110 SUBJECTS ${ }^{1}$

Age at Amputation (yr.)

Time Interval between Amputation and Interview

\begin{tabular}{|c|c|c|c|c|c|c|}
\hline & \multicolumn{3}{|c|}{ Phantom } & \multicolumn{3}{|c|}{ No Phantom } \\
\hline & $N$ & Range & Median & $N$ & Range & Median \\
\hline $\begin{array}{l}\quad<1-0 \\
1-0 \text { to } 1-11 \\
2-0 \text { to } 2-11 \\
3-0 \text { to } 3-11 \\
4-0 \text { to } 4-11 \\
5-0 \text { to } 5-11 \\
6-0 \text { to } 6-11 \\
7-0 \text { to } 7-11 \\
\text { Total }<8-0^{2}\end{array}$ & $\begin{array}{r}1 \\
1 \\
0 \\
3 \\
0 \\
7 \\
7 \\
6 \\
25\end{array}$ & $\begin{array}{l}\bar{Z} \\
\overline{<} \\
\overline{-} \text { mth. to } 42 \mathrm{yr} \text {. } \\
2-6 \text { to } 19 \mathrm{yr} . \\
1-6 \text { to } 13 \mathrm{yr} . \\
5-10 \text { to } 33 \mathrm{yr} \text {. } \\
<1 \text { mth. to } 42 \mathrm{yr} \text {. }\end{array}$ & $\begin{array}{l}3-9 \\
2-0 \\
7-0 \\
\frac{8-8}{3-6} \\
9-9 \\
8-8\end{array}$ & $\begin{array}{r}6 \\
2 \\
7 \\
3 \\
3 \\
2 \\
1 \\
2 \\
26\end{array}$ & $\begin{array}{l}5-4 \text { to } 19 \mathrm{yr} \text {. } \\
4-2 \text { to } 16 \mathrm{yr} \text {. } \\
7-3 \text { to } 40 \mathrm{yr} \text {. } \\
1-8 \text { to } 42 \mathrm{yr} \text {. } \\
14 \mathrm{yr} \text { to } 21 \mathrm{yr} \text {. } \\
1-10 \text { to } 55 \mathrm{yr} \text {. } \\
\frac{8-6}{8-6} 24 \mathrm{yr} \text {. } \\
1-10 \text { to } 55 \mathrm{yr} \text {. }\end{array}$ & $\begin{array}{l}12-2 \\
10-1 \\
17 \mathrm{yr} . \\
35 \mathrm{yr} . \\
17-6 \\
26-5 \\
1-10 \\
16-3 \\
16 \mathrm{yr} .\end{array}$ \\
\hline $\begin{array}{c}8-0 \text { to } 8-11 \\
9-0 \text { to } 9-11 \\
10-0 \text { to } 19-11\end{array}$ & $\begin{array}{r}5 \\
13 \\
41\end{array}$ & $\begin{array}{l}5-4 \text { to } 38 \mathrm{yr} \text {. } \\
0-10 \text { to } 43 \mathrm{yr} \text {. } \\
0-2 \text { to } 60 \mathrm{yr} \text {. }\end{array}$ & $\begin{array}{l}9 \text { yr. } \\
7-6 \\
2-6\end{array}$ & $\begin{array}{l}0 \\
0 \\
0\end{array}$ & - & $=$ \\
\hline
\end{tabular}

'For lack of complete information the following seven cases have been omitted from this table: From Table II, four cases of Riese and Bruck, one case of Browder and Gallagher, one case of Hécaen and Ajuriaguerra; from Table III, Case 339.

Amputation-interview intervals were compared for 25 instances of phantom and 26 instances of no phantom after amputation before age 8 years. Mann-Whitney $U=448, z=2.32, P=0.01$.

results for the subjects of group $d$ are presented in Table VI, and have been summarized in Table VII.

The previously found relationship between age at amputation and incidence of phantom holds for this group of subjects just as it did for those discussed above. A quick comparison of Table IV and VII shows very similar percentages for the several age levels.

Group d, however, allows us to isolate a second factor, that of the sensory and motor function of the extremity before its loss. All those subjects who reported phantom experiences had had sensation and/or motion in the misshapen limb before its amputation. Conversely, two of the three subjects who reported no phantom following amputation after the age of 8 years had lacked such functions in the affected structure (Cases 468 and 467). Thus, the crucial determinant is not mere chronological age but the sensory-motor experience accumulated during the years which make up that age.

\section{DISCUSSION}

If we regard the amputation phantom as a legitimate member of the class of perceptual phenomena (and I tenaciously hold to that view) then our most general finding contributes little to our understanding of the phenomenon. What other perceptual development reaches a degree of completion anywhere between the ages of 6 months and 8 years? Had we found an absolute lower age limit, and a range extending over two or three years, we might have been able to correlate the emergence of the phantom with the emergence of some other specific perceptual acquisitions. For example, having established that phantoms follow predictably upon amputation at or after the age of 8 one might be tempted to recall the findings of Brunswik and his students concerning the development of the so-called perceptual constancies: in those experiments in which the constancies were shown to improve with age, the level attained around 
age 7 or 8 years is usually that of the final adult performance, even though there may be additional improvement up to 10 or 12 years of age, which is followed by a drop during adolescence (Klimpfinger, 1933). Similarly, at 7 or 8 practically all normal children have attained the necessary stability and differentiation of perceptual functions to profit from instruction in reading and writing. True, many children are ready for these complex activities long before that age, but hardly at 6 months, or even at 18 months. Conversely, while the typical acquisitions at these early ages may be delayed somewhat in some children, they are never delayed for several years unless there is severe mental deficit, a condition which did not obtain in any of the subjects of this study. (It may however be of interest to note that, contrary to Pick's early claim, mental defective amputees appear to have normal phantom experiences (Pick, 1915; Simmel, 1959a)). An alternative hypothesis has been suggested, and received some support from the data on amputation-interview intervals. It is at least conceivable that even the very young amputee experiences a phantom transiently, an experience which typically does not persist and, in addition, cannot be recalled later. Both the transient nature of the young child's phantom and the forgetting of the experience may be due to a general instability of mnemonic processes at early ages. In addition, in so far as the distinction between reality and appearance presupposes even at the simplest level a degree of abstraction, and at least implicit verbal articulation, a phantom which had disappeared before these processes have been attained may simply lack any avenue of recall. Admittedly, this 'iceberg hypothesis' still does not account for the wide age range. It neither suggests why the phantom may, on occasion, not disappear in the very young amputee, nor why it disappears and cannot be recalled by some children having undergone amputation at a more advanced age, e.g., above the age of 5 years (eight cases: three from Table II, four from Table III, and Case 902 from Table IV). In fact, this speculation can only be justified in negative terms; on the one hand, we know a bit about perceptual and conceptual development in the child, and the data do not fit in with that knowledge; on the other hand, we know nothing concerning the development of mnemonic processes and the determinants of forgetting, and where nothing is known, anything is possible.

From the subjects with amputations of congenitally malformed extremities we have learned that phantoms follow only if the limb had had some sensory or motor function before its loss. Even though we have only sketchy information concerning the extent of pre-amputation function and deficit, I should like to suggest that the following two assumptions are more likely to be true than not:

1 When the subject is known to have walked before amputation, this implies that kinaesthesis was not completely absent in the affected extremity. It is suggested that this kinaesthetic sensitivity is probably the crucial parameter rather than the motor aspect of walking.

2 When there is sensory deficit, but not complete absence of sensation, it is unlikely that the several modalities are equally involved. It is highly probable that under those conditions the cutaneous modalities are most severely affected, or even absent, while kinaesthesis and deep pressure are less impaired, or perhaps even normal.

These two assumptions arise from as yet unpublished data which will be the subject of a future communication. Meanwhile, the reader is asked to consider them as at least reasonable hypotheses.

We can now return to the earlier hypothesis concerning phantoms after amputation in the very young. On other occasions I have argued that the phantom is a sign of a schema of the body which persists beyond the time of the loss of the limb (Simmel, 1956a and b, 1958). I have also argued that this schema is primarily a postural one, just as Head first suggested, and is built up largely from kinaesthetic and perhaps deep pressure experience (Simmel, 1960). The evidence for phantoms in at least some of the youngest amputees supports this view. At the early ages a visual or even a tactile schema of the body would seem to be precluded by the poverty of visual and tactile spatial organization. By contrast, the postural adjustments which the infant learns to make in the first few months may be regarded as evidence of the acquisition of a postural schema at that time, even though such a schema probably still lacks the fine articulation of later years which is probably largely dependent on the organization of tactile space.

\section{SUMMARY}

Data from several groups of young amputees indicate that phantoms are rarely reported if the amputation was performed before the age of 4 years; thereafter, their incidence increases, and phantoms follow predictably upon amputation at or above 8 years. Three subjects (four amputations) reported phantoms after amputation before the age of 2 years, the youngest being 6 months at the time of the surgery. It has been suggested that transitory phantoms may occur typically even in the very young amputees, that they may lack, however, the persistence of the adult phantom, and that the experience itself is forgotten. This hypothesis receives at least 
TABLE VI

PHANTOMS AFTER AMPUTATION IN CHILDHOOD OF CONGENITALLY MALFORMED EXTREMITIES

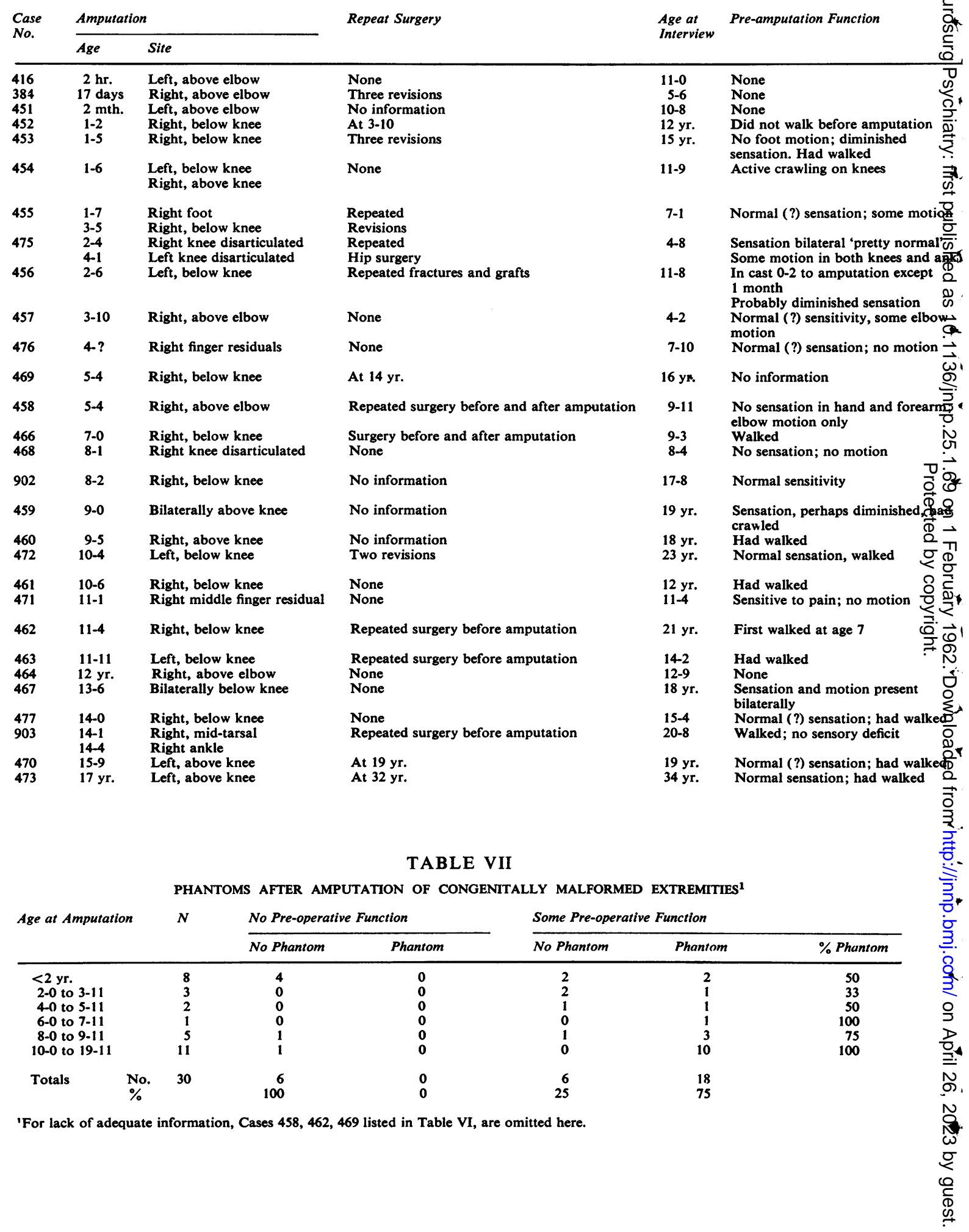


TABLE VI-continued

PHANTOMS AFTER AMPUTATION IN CHILDHOOD OF CONGENITALLY MALFORMED EXTREMITIES

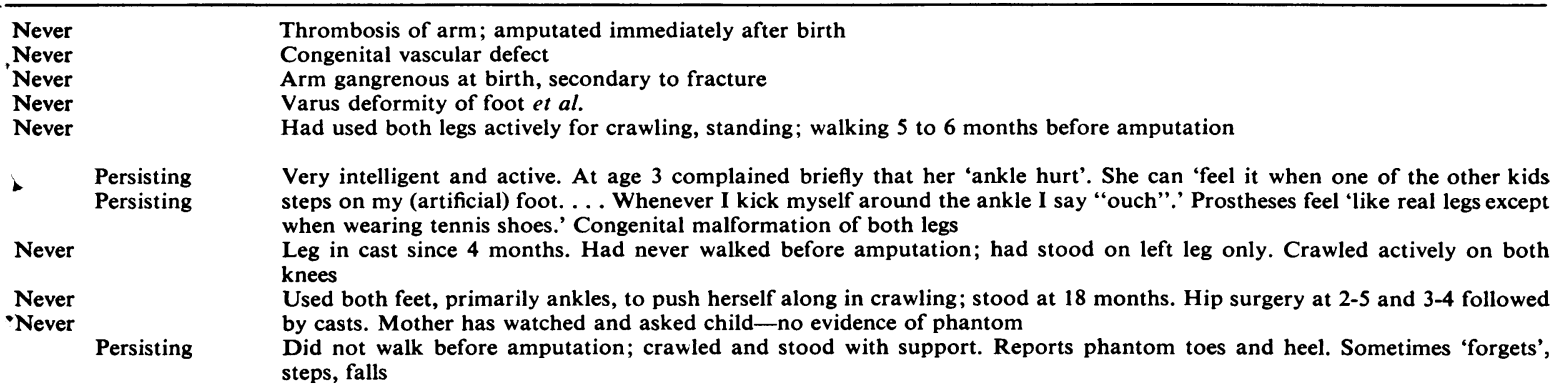

Never

Persisting?

Never?

$?$ ?

Never

Persisting

Never

Not-persisting

Persisting

Not-persisting

Persisting

Persisting

Persisting

Persisting

'Never

Persisting

Persisting

Persisting

Persisting

Persisting

\section{Some use of rudimentary forearm ending in single finger residual before amputation}

Congenital hypoplasia of hand with boneless finger buds. Child insists he feels fingers. Intelligent parents never heard child talk about phantoms before; think child may respond to examiner's suggestion

Re phantom, mother says, 'She never had anything like that'. Child assents meekly. Same on repeat interview. Reliability? Denial?

Multiple congenital abnormalities. Gigantism of forearm. According to mother, no evidence of phantom. After many questions by nurses and physicians subject says he can feel hand. Suggestion? Reliability?

In cast 2 to 14 months. Then walked in walking cast and/or elevated shoe. Feels toes only, at stump; can move them

Spina bifida; flaccid paralysis of both legs. Child 'scooted around on stomach' since 10 months. Casts before amputation. Aunt reports before amputation, 'He knew about the legs only from seeing them'

Had walked before amputation; probably no ankle motion. Pain one year before amputation. No phantom ever, according to intelligent patient and mother

Crawled until age 6, then wheelchair. Vivid phantoms persisted for at least 2 years after amputation, none since

Had walked on short leg with brace. Phantom toes at stump; can move them

In walking cast until age 5, then brace. Felt toes only for several months after amputation, until fitted with prosthesis. No

phantom since
Toes and foot sometimes feel cramped, or may itch. Twice 'forgot' and almost stenped on phantom foot

Finger residual amputated because it got in the way. Phantom finger feels the size of amputated residual. No phantom movement. Congenital absence of several fingers. No surgery, no phantom

At 7 years walked with crutches, leg hanging down in cast; eventually walking cast. Feels toes only at stump. 'You know they're not there, but you feel they are'

After amputation pain in absent leg. Now feels toes only, painless

No phantom of amputated hand remnant nor of congenitally missing forearm

Deformity of right foot; absence of left foot and toes. Now vivid phantom of right foot and toes; less vivid phantom of left lower leg. Very active; had walked, roller skated. Increasing pain and difficulty last year before amputation

Feels foot; phantom toes are 'too little' and 'sticking out of the stump'. Has stepped on phantom foot and fallen

Before amputation pes equinus. Feels foot and toes. No telescoping

Feels toes, calf, knee. No telescoping. Increasing pain and difficulty last year before amputation

Congenital elephantiasis of leg. Walked well; no casts, etc. 'Even to this day it feels like I could still move my large toe'

some support from a comparison of amputationinterview intervals. Such intervals were significantly shorter for subjects reporting phantoms than for those who did not. In a group of children who had undergone amputation of congenitally malformed extremities it could further be shown that phantoms occur only if there has been some sensory and/or motor function before the loss of the misshapen limb. It was suggested that the crucial variable here is kinaesthetic and/or deep pressure sensitivity. These findings were shown to support the hypothesis that the body schema which gives rise to the amputation phantom is basically a postural schema.

This report was prepared during the tenure of U.S.
Public Health Service Special Research Fellowship MF-1193 awarded to the writer by the National Institute of Mental Health. A supplementary grant from Brandeis University is gratefully acknowledged herewith.

\section{REFERENCES}

Browder, J., and Gallagher, J. P. (1948). Ann. Surg., 128, 456. Critchley, Macdonald (1955). Encéphale, 44, 501.

Cronholm, B. (1951). Acta psychiat. scand., Suppl. 72.

Ewalt, J. R., Randall, G. C., and Morris, H. (1947). Psychosom. Med., 9, 118.

Guéniot (1861). J. Physiol. de l'Homme et des Animaux, 4, 416.

Head, H., and Holmes, G. (1912). Lancet, 1, 144.

Hécaen, H., and Ajuriaguerra, J. de (1952). Méconnaissances et Hallucinations Corporelles. Masson, Paris.

Henderson, W. R., and Smyth, G. E. (1948). J. Neurol. Neurosurg. Psychiat., 11, 88. 
Keynes, G. (1952). The Apologie and Treatise of Ambroise Paré. University of Chicago Press, Chicago.

Klimpfinger, S. (1933). Arch. ges. Psychol., 88, 599.

Livingston, K. E. (1945). J. Neurosurg., 2, 251.

Melville, H. (1959). Moby Dick. Dell, New York, p. 507.

Mitchell, S. Weir (1871). Lippincott's Mag. pop. Lit. Sci., 8, 563.

Oldfield, R. C., and Zangwill, O. L. (1942a). Brit. J. Psychol., 32, 267.

$\longrightarrow$,

- (1943). Ibid., 33, 143.

Pick, A. (1915). Neurol. Zbl., 34, 257.

Riese, W. (1958). In Poynter, F. N. L. The History and Philosophy of Knowledge of the Brain and its Function: An Anglo-American Symposium, 1957, p. 115. Blackwell, Oxford.

_-, and Bruck, G. (1950). Rev. neurol., 83, 221.
Russell, W. R. (1959). Brain, Memory, Learning. Clarendon Press, Oxford.

Schilder, P. (1950). The Image and Appearance of the Human Body. International Universities Press, New York.

Simmel, M. L. (1956a). A.M.A. Arch. Neurol. Psychiat., 75, 637.

- (1956b). Amer. J. Psychol., 69, 529.

(1958). Proc. Amer. Philos. Soc., 102, 492

- (1959a). J. abnorm. soc. Psychol., 59, 128.

- (1959b). Amer. J. Psychother., 13, 603.

(1960). mimeo, Amer. Psychol. Ass. (to be published).

- (1961). Amer. J. Psychol., 74, 467.

Souques and Poisot (1905). Rev. neurol., 13, 1112.

Steelman, J. (1952). Personal communication.

Watson, E. J., and Johnson, A. M. (1958). Amer. J. Orthopsychiat., $28,85$.

\section{THE NOVEMBER 1961 ISSUE}

\section{THE NOVEMBER 1961 ISSUE CONTAINS THE FOLLOWING PAPERS:-}

The Recording of Lateral Popliteal Nerve Action Potentials in Man R. W. GILliatT, H. V. GOODMAN and R. G. WILLISON

A Syndrome of Continuous Muscle-fibre Activity HYAM ISAACS

Electroencephalographic Changes in Cerebellar Degenerative Lesions L. A. LIVERSEDGE and v. EMERY

Studies in Spina Bifida Cystica: I General Survey and Reassessment of the Problem Patricia ANNE DORAN and A. N. GUTHKELCH

The Prognosis of Survival from Cerebrovascular Accidents IAN D. MELVILLE and STEWART RENFREW

Intramedullary Haemangioblastoma of the Spinal Cord Associated with Pial Varicosities Simulating Intradural Angioma K. R. KRISHNAN and W. THOMAS SMITH
Controlled Multifocal Frontal Leucotomy for Psychiatric Illness H. J. CROW, R. COOPER, and D. G. PHILLIPS

Intellectual Impairment in Children with Localized Post-infantile Cerebral Lesions JOHN MCFIE

Prolonged Organic Psychosis with Recovery in Addison's Disease SAMUEL I. COHEN and I. M. MARKS Ocular Sympathetic Palsy in Periodic Migrainous Neuralgia E. A. NIEMAN and L. J. HURWITZ

Radiological and Clinical Features of an Arachnoid Cyst of the Quadrigeminal Cistern HERBERT LOURIE and ALFRED S. BERNE

Suprachiasmal Meningioma in a 2-Year-Old Child PAUL TENG

Extradural Haematoma at the Vertex G. L. ALEXANDER

Book Reviews

Index to Volume 24

Copies are still available and may be obtained from the PUBLISHING MANAGER, BRITISH MEDICAL ASSOCIATION, TAVISTOCK SQUARE, W.C.I, price 17s. 6D. 